\title{
GUIDELINES FOR PARTICIPATION
}

When submitting panel and individual paper proposals keep in mind the five participation rules developed by the APSA Council:

\section{Dual Participation}

In the Fall of 1987, in order to encourage participation by the greatest number of people, the APSA Council imposed a limit on participation in the Program. No one may participate on more than two panels listed in the program including APSA Program Committee Panels, those of APSA's Organized Sections, and those of Related Groups. The dual participation rule permits any two of the standard forms of participation --chairing a panel, acting as a discussant, or presenting a paper.

\section{Preregistration}

The APSA Council requires all program participants to preregister by June 15, 1995. Any participant who does not preregister by June 15 will not be listed in the Final Program.

\section{Exempt Participants}

Prospective participants may request of a division chair an exemption from the preregistration requirement if they are: [a] not a political scientist and [b] appearing on only one panel. An exempt participant receives a badge for admission to all Annual Meeting activities, but is not entitled to receive an Annual Meeting Program or the reduced hotel rate.

\section{Paper Delivery}

Paper presenters have two important obligations: [a] to see to it that members of your panel, especially discussants, receive your paper in time to read it carefully prior to the meetings and [b] to submit $\mathbf{5 0}$ copies of the paper to the panel paper room at the hotel by the first day of the meetings.

\section{Panel Schedule}

Panels are scheduled in 14 time slots beginning at 8:45 a.m. on Thursday and concluding at 12:30 p.m. on Sunday. Participants are expected to be available for any of the 14 time slots. 